\title{
BMJ Open Prevalence and predictors of latent tuberculosis infection among Italian State Policemen engaged in assistance to migrants: a national cross-sectional study
}

\author{
Paolo Durando, ${ }^{1,2}$ Sergio Garbarino, ${ }^{1,3}$ Andrea Orsi, ${ }^{1,2}$ Cristiano Alicino, ${ }^{1}$ \\ Guglielmo Dini, ${ }^{1}$ Alessandra Toletone, ${ }^{1}$ Fabrizio Ciprani, ${ }^{3}$ Giuseppe Conte, ${ }^{3}$ \\ Roberto Santorsa, ${ }^{3}$ Giancarlo Icardi $^{1,2}$
}

To cite: Durando $P$, Garbarino S, Orsi A, et al. Prevalence and predictors of latent tuberculosis infection among Italian State Policemen engaged in assistance to migrants: a national cross-sectional study. BMJ Open 2016;6: e012011. doi:10.1136/ bmjopen-2016-012011

- Prepublication history for this paper is available online. To view these files please visit the journal online (http://dx.doi.org/10.1136/ bmjopen-2016-012011).

PD and SG contributed equally.

Received 22 March 2016 Revised 17 May 2016 Accepted 2 August 2016

CrossMark

For numbered affiliations see end of article.

Correspondence to Dr Andrea Orsi; andrea.orsi@ unige.it

\section{ABSTRACT}

Objectives: Better knowledge about tuberculosis (TB) and latent TB infection (LTBI) epidemiology is a crucial step for the development of effective strategies towards the control and elimination of this deadliest and persistent health threat. No study has investigated LTBI epidemiology in policemen who act as an interface with cross-border migrants.

Methods: A survey to measure the LTBI prevalence and assess the demographic, professional and clinical features potentially associated with tuberculin skin test (TST) positivity was performed in Italian State Police (ISP) employees engaged, even occasionally, in relief activities, hospitality, photographical identification, escorting and accompanying of migrants, regardless of contact with active TB cases. Variables potentially associated with TST positivity were evaluated with univariate and multivariate analysis.

Results: From September to December 2014, 4225 ISP workers underwent TST screening and completed the questionnaire for data collection, according to study procedures. The TST was positive in $9.9 \%$ of individuals: no active TB cases were registered among the entire study population. Age, previous BCG vaccination and work category resulted independently associated with TST positivity.

Conclusions: This is the first study providing updated data about LTBI epidemiology among ISP employees engaged in assistance to migrants and furnish preliminary evidence of possible associations between TST positivity and different conditions that need to be deeply investigated with prospective studies.

\section{INTRODUCTION}

Tuberculosis (TB) remains one of the deadliest communicable diseases and a major public health issue worldwide. ${ }^{1}$ Even in the WHO European Region that accounted for only $4 \%$ of global TB new cases, TB remains a

\section{Strengths and limitations of this study}

- The survey investigates the prevalence of latent tuberculosis infection among Italian policemen who act as an interface with cross-border migrants.

- The survey involved a very large population and the logistic regression model provided a quantified description of the main demographic, professional and clinical variables associated with tuberculin skin test (TST) positivity.

- The main limitation of the study is its crosssectional design that prevents to monitor changes in TST results over time and to investigate the exact role of possible risk factors for tuberculosis transmission.

- A further limitation is the lack of information about previous exposure of participants to confirmed active tuberculosis cases, at both professional and community level.

persistent health threat, especially among the most vulnerable populations. ${ }^{12}$ Moreover, in times of economic recession, the groups at higher risk of TB including homeless people, migrants, prisoners, as well as smokers and alcohol consumers could widen, highlighting the possible detrimental impact of socioeconomic inequalities on the disease. ${ }^{34}$

Latent TB infection (LTBI) is a keystep of the natural history of Mycobacterium tuberculosis infection and one-third of the world's population is estimated to have this condition. ${ }^{4}$ Studies suggest that persons with LTBI present a lifetime risk to develop active TB estimated from $5 \%$ to $15 \%$, representing the 'seedbeds' of TB in the community. ${ }^{4}$

Thus, early diagnosis and treatment of LTBI are crucial to reach the ultimate goal of TB control and elimination. ${ }^{4}$ As highlighted 
in the recently published global framework towards TB elimination in low-incidence countries, the screening of LTBI should be considered in risk groups in order to promptly detect and manage this condition. ${ }^{5}$

To date, tuberculin skin test (TST) remains the conventional and most used test for the screening of LTBI, even though there are some well-known limitations of the assay. ${ }^{6-9}$

Italian State Police (ISP) are not routinely tested for TST reactivity. However, two circulars of the Department of Public Safety of the Italian Ministry of Interior, released in July 2014, established that all ISP engaged in relief and welcome activities, especially towards crossborder migrants, should undergo LTBI testing with TST in order to identify individuals affected by this condition among policemen who worked in particular conditions (eg, long contact indoor or with low air exchange, contact with symptomatic individuals without diagnosis of active TB or in crowded conditions). ${ }^{10}{ }^{11}$ ISP involved in this screening programme have been engaged in different national and international assistance activities and relief programme oriented to migrants, such as 'Mare Nostrum' operation, 'Triton operation' and similar, all consisting of an empowerment of the migration flows control activities towards the improvement of maritime security, the patrol of sea lanes and the relief and assistance to migrants. ${ }^{12}$

In fact, due to geopolitical reasons, some EU countries are nowadays facing epochal inflows of new economic immigrants and asylum seekers. In particular, during the last 3 years migration flows across Mediterranean sea have become an international emergency: considering the 2012-2014 period, more than 200000 people, mainly hailing from areas at high circulation of $M$. tuberculosis (namely, Syria: 24.9\%; Eritrea: 20.2\%; sub-Sahara: $12 \%)$, reached Italian coasts through illegal travels from northern African and Middle-East countries. ${ }^{13}$

To the best of our knowledge, no study has investigated the epidemiology of LTBI in groups of policemen who act as an interface with migrants. In the quest to bridge this gap, a survey to measure the prevalence of LTBI and assess the demographic, professional and clinical features potentially associated with TST positivity was performed in ISP engaged in relief and assistance activities to cross-border migrants.

\section{METHODS}

\section{Study design and population}

A cross-sectional survey was carried out between September and December 2014. Study population involved all ISP engaged, even occasionally, in relief activities, hospitality, photographical identification, escorting of migrants, regardless from the occurrence of contact with migrants with active TB. The ISP engaged in these tasks has been identified by the chiefs of the local offices they belong, on the basis of their occupational history.
These policemen were actively summoned to undergo LTBI testing with TST, as prescribed by the abovementioned circulars. ${ }^{10}{ }^{11}$ Data about demographic, professional and clinical characteristics of the population have been obtained, through a standardised questionnaire, by the ISP medical staff coordinated by the Central Directorate of Health of the Italian Ministry of Interior.

\section{Diagnostic method: TST technique}

Screening for LTBI was carried out, by trained healthcare workers, with execution of the TST using the Mantoux technique, as recommended by the "Guidelines for the control of TB", proposed by the Minister of Health, pursuant to article 115, paragraph 1, letter b) of legislative decree number 31 March 1998..$^{14} 15$

A standard dose of purified protein derivative (PPD) of tuberculin was slowly injected intradermally into the inner surface of the forearm. The skin was slightly stretched, and the needle held almost parallel to the skin surface with the bevel facing upwards. The injection was made with a plastic disposable syringe, with a shortbevel needle (25-gauge). The reaction was read by measuring the diameter of induration across the forearm (perpendicular to the long axis) in millimetres by palpation and using a ruler. An induration $\geq 10 \mathrm{~mm}$ in healthy individuals was considered positive. The skin test reaction should be read between 48 and 72 hours after administration.

The tests were performed at the ISP Health Office to which personnel involved belong or at public facilities (ie, Local Health Authority infectious disease centres, universities, hospitals) previously identified as suitable by the ISP Health Service.

According to the above-mentioned circulars, TST positive cases were also tested with an interferon- $\gamma$ release assay (IGRA) and underwent chest radiography to exclude the diagnosis of active $\mathrm{TB}$ or to confirm the diagnosis of LTBI. ISP Health Offices routinely collected information on active TB cases among ISP. ${ }^{10}{ }^{11}$ In the case of the diagnosis of active TB, ISP worker is temporarily removed from his task and adequately treated by an infectious-disease specialist.

\section{Data collection}

A standardised questionnaire has been elaborated at the Department of Health Sciences of the University of Genoa, in order to describe the demographic and professional characteristics of the study population and assess their possible association with TST positivity. The questionnaire is composed of three sections: (1) sociodemographic, collecting information about age, gender, nationality, place of birth and educational level; (2) professional: collecting information about the current work assignment within the ISP as well as the length of service; (3) clinical, collecting information relating to previous BCG vaccination and the health status. 
In particular, employees included in the study have been classified into five work categories on the basis of their current assigned bureau. These five categories are reported below together with a brief description of the specific tasks related to immigration assistance or control: (1) Territory Control Service or Mobile Units (category 1) include ISP employed in identity checks and monitoring their respective territories in order to safeguard public order and security and to prevent crime and monitor immigration; (2) Central Police Station or Police Academy (category 2) include ISP mainly employed in office tasks and sometimes in immigration monitoring; (3) Community Police Office or Immigration Office (category 3) include ISP mainly employed in office tasks for immigration administrative issues and monitoring; (4) Forensic Science Police Service (category 4) include ISP employed in collection, preservation and analysis of scientific evidence (ie, fingerprinting and mugshot) during immigrants' landings; (5) Railway Police Service or Immigration and Border Police (category 5) include ISP responsible for immigration, citizenship and border control at both central and local level with many land (Railway Police Service), air and maritime border police offices. The service is also responsible for passport control, the issuing of residence permits, transporting immigrants as well as the prevention and control of illegal immigration. In airports the border police are in charge of security (hand baggage searches) and immigration checks.

\section{Statistical analysis}

All the information collected through the questionnaire and the TST results were entered into a data sheet and analysed using Epi-Info (CDC, V.7.0, Atlanta, USA) and JMP (SAS System, V.10.0).

Continuous numeric variables were summarised as mean and SD and/or, when appropriate, median and IQR. Nominal and ordinal categorical variables were summarised in the form of percentage proportions and 95\% CI.

Variables potentially associated with TST positivity were evaluated with univariate analysis and multivariate logistic model. Multicollinearity between variables was assessed. All tests were two-tailed and a $\mathrm{p}<0.05$ was determined to represent statistical significance.

\section{Ethics}

All the activities of the survey were performed in compliance with the circulars of the Department of Public Safety of the Italian Ministry of Interior, prescribing the screening of LTBI within ISP employees engaged in relief and assistance activities to cross-border migrants, ${ }^{10}{ }^{11}$ and according to the Declaration of Helsinki.

The Central Directorate of Health invited all eligible employees to participate in the screening programme for LTBI. Those who have not agreed to participate in the programme signed a letter of dissent to participation. All included individuals were informed by a physician of ISP Health Service about the rational and the procedures of the study and signed an informed consent. All demographic, professional and clinical data were completely anonymised and were analysed according to privacy legislation. ${ }^{16}$

\section{RESULTS}

Demographic, professional and clinical characteristics of the study population

Overall, 4352 ISP employees were actively summoned to undergo LTBI testing with TST by the chiefs of the local offices they belong to.

From September to December 2014, 4225 (97.1\%) out of the 4352 eligible workers underwent TST screening, according to the procedures described above, and completed the questionnaire. Individuals who did not undergo TST screening were excluded from the final analysis $(127 / 4352,2.9 \%)$. These individuals did not differ significantly from the study population with respect to the majority of collected variables, with the exception of age, length of service and work category. In particular, the excluded individuals were younger (40.1 vs 43.8, $\mathrm{p}<0.001$ ) and with a lower length of service $(17.8$ vs $20.5, \mathrm{p}<0.001)$ compared to individuals included in the study population. Moreover, individuals included in work category 1 had a higher compliance to TST screening compared to employees belonging to other work categories $(99.4 \%$ vs $96.8 \%$, $\mathrm{p}<0.001)$.

The main demographic, professional and clinical characteristics of the study population are outlined in table 1.

The majority of the employees were men $(3462 / 4225$, $81.9 \%)$, born in Italy $(3913 / 4225,97.6 \%)$, and the mean (SD) age was 43.8 (7.8) years. Within the Italy born individuals, the majority of employees were born in the South $(2367 / 3913,60.5 \%)$. With respect to education level, $2250(70.4 \%)$ of 4225 individuals reached secondary degree.

Mean (SD) length of service was 20.5 (8.3) years and almost half of the employees (2062/4225, 48.8\%) belonged to third work category, followed by second work category $(1027 / 4225,24.3 \%)$.

Previous BCG immunisation had been reported by $114(2.7 \%)$ of the 4225 employees. Mean age of individuals vaccinated with BCG were significantly higher than that of individuals not vaccinated (46.3 vs 43.7, $\mathrm{p}=0.001$ ). In particular, more than $60 \%$ of vaccinated employees were aged $>45$ years. A higher proportion of previous vaccination was registered both in foreign individuals compared to individuals born in Italy $(10.5 \%$ vs $2.6 \%, \mathrm{p}<0.001)$ and among employees included in work category 5 compared to individuals belonging to the remaining work categories $(6.2 \%$ vs $2.5 \%, \mathrm{p}=0.002)$.

TST was positive in $9.9 \%(418 / 4225)$ of individuals. No active TB cases were registered within this group and among the entire study population. 
Table 1 Demographic, professional and clinical characteristics of a cohort of ISP workers $(n=4225)$

\begin{tabular}{|c|c|c|}
\hline Variables & $\mathbf{N}$ & $\%(95 \% \mathrm{Cl})$ \\
\hline Total number or participants in the study & 4225 & 100 \\
\hline Mean age, year (SD) & $43.8(7.8)$ & \\
\hline \multicolumn{3}{|l|}{ Gender } \\
\hline Male & 3462 & $81.9(80.7$ to 83.1$)$ \\
\hline Female & 763 & $18.1(16.9$ to 19.2$)$ \\
\hline \multicolumn{3}{|l|}{ Place of birth (overall, $\mathrm{N}=4008$ ) } \\
\hline Italy & 3913 & $97.6(97.1$ to 98.1$)$ \\
\hline Foreign & 95 & $2.4(1.9$ to 2.9$)$ \\
\hline \multicolumn{3}{|l|}{ Place of birth (within Italy; $N=3913$ ) } \\
\hline North & 839 & $21.4(20.2$ to 22.8$)$ \\
\hline Centre & 707 & $18.1(16.9$ to 19.3$)$ \\
\hline South & 2367 & 60.5 (58.9 to 62.0$)$ \\
\hline \multicolumn{3}{|l|}{ Place of birth (foreign; $\mathrm{N}=95$ ) } \\
\hline OECD & 77 & $81.1(71.7$ to 88.4$)$ \\
\hline Non-OECD & 18 & $18.9(11.5$ to 28.8$)$ \\
\hline \multicolumn{3}{|l|}{ Educational level $(\mathrm{N}=3195)$} \\
\hline Lower secondary school & 549 & $17.2(15.9$ to 18.5$)$ \\
\hline Upper secondary school & 2250 & $70.4(68.8$ to 72.0$)$ \\
\hline Higher education & 396 & $12.4(11.3$ to 13.6$)$ \\
\hline Mean length of service, year (SD) & $20.5(8.3)$ & \\
\hline \multicolumn{3}{|c|}{ Place of bureau to which ISP worker is assigned } \\
\hline North & 1641 & $38.8(37.4$ to 40.3$)$ \\
\hline Centre & 810 & $19.2(18.0$ to 20.4$)$ \\
\hline South & 1774 & $42.0(40.5$ to 43.5$)$ \\
\hline \multicolumn{3}{|l|}{ Work category } \\
\hline 1 & 507 & $12.0(11.0$ to 13.0$)$ \\
\hline 2 & 1027 & 24.3 (23.0 to 25.6$)$ \\
\hline 3 & 2062 & $48.8(47.3$ to 50.3$)$ \\
\hline 4 & 434 & 10.3 (9.4 to 11.2$)$ \\
\hline 5 & 195 & $4.6(4.0$ to 5.3$)$ \\
\hline \multicolumn{3}{|l|}{ Previous BCG vaccination } \\
\hline No & 4111 & 97.3 (96.8 to 97.8 ) \\
\hline Yes & 114 & 2.7 (2.2 to 3.2$)$ \\
\hline \multicolumn{3}{|l|}{ TST result } \\
\hline Negative & 3807 & 90.1 (89.2 to 91.0$)$ \\
\hline Positive & 418 & $9.9(9.0$ to 10.8$)$ \\
\hline
\end{tabular}

Univariate and multivariate analysis of variables associated with TST positivity

Univariate and multivariate analysis of variables associated with TST positivity is outlined in table 2.

At univariate analysis, the prevalence of TST positivity statistically increased with age and length of services. Moreover, it resulted higher between employees born in foreign countries and those who received previous BCG vaccination, whereas it resulted lower in individuals with higher study degree and in employees included in categories 1-4.

Length of service and place of birth within Italy were excluded from the final multivariate analysis for collinearity. Also, place of bureau to which ISP worker is assigned was excluded from the multivariate analysis because it is not informative about the current workplace where ISP act as an interface with migrants. The multivariate logistic regression model demonstrated that 1 year increment in age and previous BCG vaccination were significantly associated with an increased probability of TST positivity, whereas individuals belonging to work categories $1-4$ had a significantly lower probability to result in TST positive (table 2).

\section{DISCUSSION}

This national study, performed by the ISP Health Offices in the context of an extensive screening programme coordinated by the Central Directorate of Health of the Italian Ministry of Interior, furnishes the first epidemiological picture of the prevalence of LTBI among the ISP workers engaged in relief and assistance activities to cross-border migrants, and also contributes to improve the knowledge of the risk factors associated with this condition.

The overall prevalence of TST positivity among ISP employees was equal to $9.9 \%$. Interestingly, this figure is lower than LTBI prevalence recorded among healthcare 
Table 2 Univariate and multivariate analysis of demographic, professional and clinical characteristics associated with TST positivity in a cohort of ISP workers ( $\mathrm{n}=4225$ )

\begin{tabular}{|c|c|c|c|c|c|c|c|}
\hline \multirow[b]{2}{*}{ Variables } & \multirow[b]{2}{*}{ Overall } & \multirow[b]{2}{*}{$\begin{array}{l}\text { TST positive } \\
\text { result }\end{array}$} & \multirow[b]{2}{*}{$\%(95 \% \mathrm{Cl})$} & \multicolumn{2}{|l|}{ Univariate analysis } & \multicolumn{2}{|c|}{ Multivariate analysis } \\
\hline & & & & OR (95\% Cl) & $p$ Value & OR (95\% Cl) & $p$ Value \\
\hline Age (per year increase) & & & & $1.07(1.05$ to 1.09$)$ & $<0.001$ & $1.07(1.05$ to 1.10$)$ & $<0.001$ \\
\hline \multicolumn{8}{|l|}{ Gender } \\
\hline Female & 763 & 72 & $9.4(7.5$ to 11.8$)$ & Reference & & Reference & \\
\hline Male & 3462 & 346 & $10.0(9.0$ to 11.1$)$ & 1.07 (0.8 to 1.4$)$ & 0.6 & 1.19 (0.86 to 1.68$)$ & 0.3 \\
\hline \multicolumn{8}{|l|}{ Place of birth } \\
\hline Italy & 3913 & 377 & 9.6 (8.7 to 10.6$)$ & Reference & & Reference & \\
\hline Foreign & 95 & 20 & 21.1 (13.4 to 30.6$)$ & 2.5 (1.5 to 4.1$)$ & 0.001 & 1.55 (0.73 to 2.99$)$ & 0.2 \\
\hline \multicolumn{8}{|l|}{ Place of birth (within Italy) } \\
\hline North & 839 & 99 & 11.8 (9.7 to 14.2$)$ & $1.4(1.1$ to 1.8$)$ & 0.02 & & \\
\hline Centre & 707 & 67 & 9.5 (7.5 to 11.9$)$ & $1.1(0.8$ to 1.4$)$ & 0.6 & & \\
\hline South & 2367 & 211 & 8.9 (7.8 to 10.2$)$ & Reference & & & \\
\hline \multicolumn{8}{|l|}{ Educational level } \\
\hline Lower secondary school & 549 & 72 & 13.1 (10.5 to 16.2$)$ & Reference & & Reference & \\
\hline Upper secondary school & 2250 & 207 & $9.2(8.1$ to 10.5$)$ & $0.7(0.5$ to 0.9$)$ & 0.008 & $0.98(0.72$ to 1.36$)$ & 0.93 \\
\hline Higher education & 396 & 30 & 7.6 (5.4 to 10.6$)$ & 0.5 (0.3 to 0.8$)$ & 0.006 & $0.66(0.40$ to 1.08$)$ & 0.10 \\
\hline Length of service (per year increase) & & & & $1.06(1.05$ to 1.08$)$ & $<0.001$ & & \\
\hline \multicolumn{8}{|l|}{ Work category } \\
\hline 1 & 507 & 51 & $10.1(7.7$ to 13.0$)$ & $0.53(0.33$ to 0.85$)$ & 0.009 & $0.54(0.28$ to 1.0$)$ & 0.049 \\
\hline 2 & 1027 & 94 & $9.2(7.5$ to 11.1$)$ & 0.48 (0.31 to 0.74$)$ & 0.001 & 0.52 (0.32 to 0.84$)$ & 0.008 \\
\hline 3 & 2062 & 192 & $9.3(8.1$ to 10.6$)$ & 0.49 (0.33 to 0.73$)$ & 0.001 & 0.54 (0.34 to 0.86$)$ & 0.01 \\
\hline 4 & 434 & 47 & $10.8(8.2$ to 14.1$)$ & 0.58 (0.36 to 0.93$)$ & 0.025 & 0.55 (0.32 to 0.94$)$ & 0.03 \\
\hline 5 & 195 & 34 & 17.4 (12.8 to 23.4$)$ & Reference & & Reference & \\
\hline \multicolumn{8}{|l|}{ Previous BCG vaccination } \\
\hline No & 4111 & 335 & $8.1(7.4$ to 9.0$)$ & Reference & & Reference & \\
\hline Yes & 114 & 83 & $72.8(64.0$ to 80.1$)$ & 30.2 (19.9 to 46.9$)$ & $<0.001$ & $21.0(12.9$ to 34.9$)$ & $<0.001$ \\
\hline
\end{tabular}


workers employed in low TB incidence countries, traditionally considered a high-risk category. Indeed, the available data from studies performed in this work category, by using the TST assay to screen LTBI, showed prevalence figures ranging between $16.2 \%$ and $34 \% .{ }^{17-19}$

However, in two cited studies the proportions of BCG vaccinated individuals were higher than in our study population and this finding may have affected the rate of TST positivity. In fact, the prevalence of LTBI based on IGRA positivity results were $7.6 \%$ and $1 \%$, respectively. ${ }^{17} 18$

In our study the TST positivity rate steadily increased with the age of the employees, from $1.6 \%$ in individuals aged $21-30$ years to $14.1 \%$ in those aged $>50$ years. This trend may be attributable to a 'cohort effect' related to the different circulation of M. tuberculosis in the 1970s and earlier in Italy. ${ }^{20}{ }^{21}$ Indeed, Italy has been classified by $\mathrm{WHO}$ as low TB incidence country since 1974 , while the crude annual total incidence of TB was higher than 10 cases per 100000 inhabitants in previous decades, thus determining an increased risk of exposure to infectious cases of TB among the general population. ${ }^{22}$ The independent association between TST positivity and increasing age was further confirmed by a multivariate analysis that demonstrated a 7\% increase in the odds for TST positivity per 1 year. A similar finding has been previously reported by D'Amelio $e t a l^{23}$ in a large population of Italian military recruits aged 18-23 years.

TST positivity rates stratified by age class registered in the study population were not comparable with prevalence of LTBI in Italian general population, as no data are available in literature. However, the prevalence of TST positivity registered in policemen aged $<30$ years $(1.6 \%)$ were superimposable to the rates reported in Italian healthcare students of the same age $(0.8-3.8 \%)$ and in Italian military recruits aged 18-23 years (4\%) ${ }^{23-28}$ Moreover, previous studies carried out among military recruits from countries with epidemiological pattern similar to Italy, have obtained comparable TST positivity rate in individuals younger than 35 years. In particular, a study, conducted in 953 Greek military recruits with a mean age of $23.5( \pm 6.4)$ years, reported a prevalence of positive TST individuals amounting to $3.9 \% .^{29}$ A previous study found a prevalence of TST positivity of $3.5 \%$ among 44128 US Navy recruits aged $17-35$ years. ${ }^{30}$

With respect to BCG vaccination, only $2.7 \%$ of individuals reported previous immunisation. Although an anamnestic bias could underestimate this figure, it should be underlined that ISPs have never been considered as a target for this preventive practice. In our population, previous BCG vaccination was the strongest independent predictor of TST positivity, in line with the results of other recent studies. ${ }^{25} 31-33$

The last variable independently associated with TST positivity resulted in the work category. In particular, categories 1-4 showed lower odds of resulting positive at TST than category 5. The classification of work categories exclusively on the basis of the current assigned bureau as well as the lack of information regarding previous professional or household exposure to active TB cases prevent any definitive conclusion about the professional TB risk pattern of these workers. However, data from international literature reported that active pulmonary TB among immigrants entering a new country is infrequent with a rate of nearly 3.5 cases per 1000 documented immigrants. ${ }^{34}$ Considering also the feature and the timing of contact with possible active TB cases during immigrant assistance and control procedures, it appears unlikely that the transmission of the microorganism to ISP could have occurred in this context. Therefore, we can speculate that previous household exposure or previous work which led to contact in enclosed spaces with high-risk categories such as prisoners, migrants living in poor conditions in the host country, homeless, etc, could explain this finding.

With respect to infection control practices, the abovementioned circulars recommended to all ISP the adoption of adequate personal protective equipment (PPE) in all cases of possible exposure to biological agents. Moreover, specific PPE to prevent airborne and droplets transmissible diseases are available for ISP. Nevertheless, no data about the correct use of PPE in the different work categories are available.

Our results suggest the opportunity to gain more knowledge about the occupational hazard of TB among policemen who act as an interface with migrants or are exposed to other high-risk groups. In particular, prospective cohort studies could exhaustively investigate the role of all possible risk factors for TB transmission, thus contributing to improve the risk assessment of $\mathrm{TB}$ among this work category.

From a public health standpoint, this study can contribute to furnish novel epidemiological insights useful to target the priority interventions recommended for the elimination of TB in low-incidence countries. Indeed, these actions include the identification of highrisk groups and the implementation of screening for active TB and LTBI in vulnerable population and TB contacts. $^{535}$

Some limitations of the present study need to be highlighted. The main limitation was the cross-sectional design that prevents to monitor changes in TST results over time and to investigate the exact role of possible risk factors for TB transmission. However, this analysis involved, for the first time, a very large population and the logistic regression model provided a quantified description of the main demographic, professional and clinical variables associated with TST positivity. Moreover, the results obtained in the present study appear robust as the compliance to the study procedure among eligible individuals was very high $(97.1 \%)$.

As mentioned above, a further limit involved the lack of information about previous exposure to confirmed active TB cases, at both professional and community levels (family, social activities, etc) and previous history 
of active TB. Furthermore, no data about previous TST administration, performed before or during engagement in police force, were obtained.

Finally, the TST is a highly 'operator-dependent' assay and requires skilled healthcare personnel for placement and interpretation. Nonetheless, it remains the conventional and most used test for the screening of LTBI. ${ }^{6-9}$

In conclusion, this study provides updated data about the prevalence of LTBI among ISP employees engaged in rescue and assistance operations to cross-border migrants. Furthermore, our results furnish preliminary evidence of a possible association between TST positivity and different variables, in particular among specific work tasks, which need to be more deeply investigated with properly designed studies, as already planned by the Italian Ministry of Interior.

The ultimate goal is to better understand the risk of TB acquisition in this peculiar employee population, in order to implement future strategies shared at Italian and European levels, including adequate occupational healthcare surveillance programmes, based on periodic critical assessment of the obtained results.

These activities could represent a useful integration of the global strategy for the control and elimination of TB in low-incidence areas.

\section{Author affiliations}

${ }^{1}$ Department of Health Sciences, University of Genoa, Genoa, Italy

${ }^{2}$ IRCCS AOU San Martino-IST, Genoa, Italy

${ }^{3}$ State Police Health Service Department, Ministry of Interior, Rome, Italy

Twitter Follow Cristiano Alicino at @CriAlicino

Acknowledgements Authors wish to thank Health Offices of Central ISP stations, Mobile Units and Police Academies; Dr Vittorio Pisani, Central Directorate of Immigration and Border Police; Administrative Office for Technical and Management Services of Public Safety Department, Ministry of Interior, Italy. Authors wish to particularly thank Massimo Troisi, Lorenzo Bernardini, Filippo Roccia and Francesca Cozzone.

Contributors PD conceived and designed the study, analysed the data and revised the paper. SG designed the research, collected data, cleaned and analysed the data and revised the paper. AO, CA, GD and AT cleaned and analysed the data, and drafted and revised the paper. FC, GC and RS collected the data and revised the paper. GI conceived and designed the research and revised the paper.

Competing interests None declared.

Patient consent Obtained.

Ethics approval The Central Directorate of Health of Italian Ministry of Interior approved the analysis of anonymised data and the publication of the results for scientific purposes and a formal approval by the Ethics Committee of Liguria Region was obtained.

Provenance and peer review Not commissioned; externally peer reviewed.

Data sharing statement No additional data are available.

Open Access This is an Open Access article distributed in accordance with the Creative Commons Attribution Non Commercial (CC BY-NC 4.0) license, which permits others to distribute, remix, adapt, build upon this work noncommercially, and license their derivative works on different terms, provided the original work is properly cited and the use is non-commercial. See: http:// creativecommons.org/licenses/by-nc/4.0/

\section{REFERENCES}

1. World Health Organization. Global tuberculosis report 2015. WHO/ $H T M / T B / 2015.22$. Geneva, World Health Organization, 2015.

2. Odone A, Tillmann T, Sandgren A, et al. Tuberculosis among migrant populations in the European Union and the European Economic Area. Eur J Public Health 2015;25:506-12.

3. Odone A, Signorelli C, Rodrigues LC. Tuberculosis and the economic crisis: an old threat for the new European agenda. Scand J Public Health 2014;42:834-5.

4. Getahun $\mathrm{H}$, Matteelli $\mathrm{A}$, Chaisson RE, et al. Latent Mycobacterium tuberculosis infection. N Engl J Med 2015;372:2127-35.

5. Lönnroth K, Migliori GB, Abubakar I, et al. Towards tuberculosis elimination: an action framework for low-incidence countries. Eur Respir J 2015;45:928-52.

6. Trajman A, Steffen RE, Menzies D. Interferon gamma release assays versus tuberculin skin testing for the diagnosis of latent tuberculosis infection: an overview of the evidence. Pulm Med2013;2013:601737.

7. Schluger NW. Advances in the diagnostics of latent tuberculosis infection. Semin Respir Crit Care Med 2013;34:60-6.

8. Lalvani A, Pareek M. A 100 year update on diagnosis of tuberculosis infection. Br Med Bull 2010;93:69-84.

9. Lamberti M, Uccello R, Monaco MG, et al. Tuberculin skin test and Quantiferon test agreement and influencing factors in tuberculosis screening of healthcare workers: a systematic review and meta-analysis. J Occup Med Toxicol 2015;10:2.

10. Department of Public Safety of the Italian Ministry of Interior. Circular N. 556/A. 1/1/132/14, 4 July 2014.

11. Department of Public Safety of the Italian Ministry of Interior. Circular N. 850/A P.1-2639, 9 July 2014.

12. http://www.marina.difesa.it/EN/operations/Pagine/MareNostrum.aspx (accessed 22 Mar 2016)

13. Belfiore C, Bruti V, Ciprani F, et al. Migrants' health and risk of infection for workers attending migratory emergency operations: the experience of the Italian national police. Riv It Med Leg 2/2015

14. Italian Ministry of Health. Circular N. 850/A P1-2161, 3 April 2002 (Infezione Tubercolare: indagini di screening nel personale della Polizia di Stato)

15. Italian Ministry of Health. Circular N. 850/A P1-1505, 25 March 2009 (Misure procedurali per la tutela degli operatori della Polizia di Stato dal rischio di infezione tubercolare).

16. Italian Law decree n.196, 30 June 2003 (article 24). http://www. camera.it/parlam/leggi/deleghe/03196dl.htm (accessed 22 Mar 2016).

17. Khanna P, Nikolayevskyy V, Warburton F, et al. Rate of latent tuberculosis infection detected by occupational health screening of nurses new to a London teaching hospital. Infect Control Hosp Epidemiol 2009;30:581-4.

18. Soborg B, Andersen AB, Larsen HK, et al. Detecting a low prevalence of latent tuberculosis among health care workers in Denmark detected by $\mathrm{M}$. tuberculosis specific IFN-gamma whole-blood test. Scand J Infect Dis 2007;39:554-9.

19. Kralj N, Hofmann F, Michaelis M. Zur Methodik der Tuberkulosefrüherkennung bei arbeitsmedizinischen Vorsorgeuntersuchungen im Gesundheitsdienst. Arbeitsmed Sozialmed Umweltmed 1997;32:50-4.

20. Winqvist N, Björk J, Miörner $\mathrm{H}$, et al. Long-term course of Mycobacterium tuberculosis infection in Swedish birth cohorts during the twentieth century. Int $J$ Tuberc Lung Dis 2011;15:736-40.

21. Winston CA, Navin TR. Birth cohort effect on latent tuberculosis infection prevalence, United States. BMC Infect Dis 2010;10:206.

22. Moro ML, Malfait $P$, Salamina $G$, et al. Tuberculosis in Italy: available data and open questions. Epidemiol Prev 1999;23:27-36.

23. D'Amelio R, Stroffolini T, Biselli R, et al. Tuberculin skin reactivity in Italian military recruits tested in 1996-1997. Eur J Clin Microbiol Infect Dis 2000;19:200-4.

24. Durando P, Sotgiu G, Spigno F, et al. Latent tuberculosis infection and associated risk factors among undergraduate healthcare students in Italy: a cross-sectional study. BMC Infect Dis 2013:13:443.

25. Durando $\mathrm{P}$, Alicino C, Orsi A, et al. Latent tuberculosis infection among a large cohort of medical students at a teaching hospital in Italy. Biomed Res Int 2015;2015:746895.

26. Sernia S, Ortis M, Antoniozzi T, et al. Latent tuberculosis infection: prevalence amongst healthcare students at the Sapienza University of Rome (Italy). Ig Sanita Pubbl 2014;70:393-400.

27. Lamberti M, Muoio M, Monaco MG, et al. Prevalence of latent tuberculosis infection and associated risk factors among 3,374 healthcare students in Italy. J Occup Med Toxicol 2014;9:34.

28. Lamberti M, Uccello R, Monaco MG, et al. Prevalence of latent tuberculosis infection and associated risk factors among 1557 nursing students in a context of low endemicity. Open Nurs $J$ 2015;9:10-4. 
29. German V, Giannakos G, Kopterides P, et al. Prevalence and predictors of tuberculin skin positivity in Hellenic Army recruits. BMC Infect Dis 2006;6:102.

30. Smith B, Ryan MA, Gray GC, et al. Tuberculosis infection among young adults enlisting in the United States Navy. Int J Epidemiol 2002;31:934-9.

31. McKay A, Kraut A, Murdzak C, et al. Determinants of tuberculin reactivity among health care workers: interpretation of positivity following BCG vaccination. Can J Infect Dis 1999;10:134-9.

32. Lee SW, Oh SY, Lee JB, et al. Tuberculin skin test distribution following a change in BCG vaccination policy. PLOS ONE 2014;9: e86419.
33. Vinton $\mathrm{P}$, Mihrshahi S, Johnson $\mathrm{P}$, et al. Comparison of QuantiFERON-TB Gold In-Tube Test and tuberculin skin test for identification of latent Mycobacterium tuberculosis infection in healthcare staff and association between positive test results and known risk factors for infection. Infect Control Hosp Epidemiol 2009;30:215-21.

34. Arshad S, Bavan L, Gajari K, et al. Active screening at entry for tuberculosis among new immigrants: a systematic review and meta-analysis. Eur Respir J 2010;35:1336-45.

35. Getahun H, Matteelli A, Abubakar I, et al. Management of latent Mycobacterium tuberculosis infection: WHO guidelines for low tuberculosis burden countries. Eur Respir J 2015;46:1563-76. 